\title{
Evaluation of the qualitative parameters of raw sheep's milk with the potential for the production of traditional artisanal cheese
}

\author{
Stanko Stankov ${ }^{1 *}$, Hafize Fidan ${ }^{1}$, Tatyana Balabanova ${ }^{2}$, Eva Dimitrova $^{3}$, and Salam A. Ibrahim ${ }^{4}$ \\ ${ }^{1}$ Department of Nutrition and Tourism, Faculty of Economics, University of Food Technologies, 4002 Plovdiv, Bulgaria \\ 2 Department of Milk and Dairy products Technology, Technological Faculty, University of Food Technologies, 4002 Plovdiv, \\ Bulgaria \\ ${ }^{3}$ Department of Informatics and Statistics, Faculty of Economics, University of Food Technologies, 4002 Plovdiv, Bulgaria \\ ${ }^{4}$ Food Microbiology and Biotechnology Laboratory, North Carolina Agricultural and Technical State University, Greensboro, NC \\ 27411, USA
}

\begin{abstract}
The aim of the present study was to investigate the physicochemical and microbiological profile of indigenous sheep's milk with the potential for the production of artisanal cheese. The data showed the changes in lactation stages (between April and August) up to 2 hours following manual milk production. The quality of raw milk in the production of brined cheese using traditional technology was assessed. The amount of dry matter was $21.36 \%$ in April and $19.85 \%$ in August at the end of lactation. The fat content from April to August was between $8.62 \%$ and $8.03 \%$, preserving the values reported. The protein composition of raw milk varied between $5.52-6.61 \%$. In the microbiological evaluation of raw sheep's milk after milking $\left(35.3^{\circ} \mathrm{C}\right)$, the total microbial contamination was in the range of $1.3 \times 10^{6}$ to $1.4 \times 10^{6} \mathrm{CFU} / \mathrm{mL}$ under current conditions. The results obtained in this paper give rise to more in-depth studies on the application of raw sheep's milk in the production of traditional artisanal cheeses.
\end{abstract}

\section{Introduction}

Sheep's milk and dairy products derived from it have been an integral part of human nutrition for centuries primarily due to their micro-and macronutrients [1].

Bulgaria and many countries in the Balkan Peninsula produce a wide variety of dairy products via milk from small ruminants, particularly sheep and goats [2], which are now valued as part of the food tradition. Most of the products obtained from milk have distinctive organoleptic characteristics due to the fatty acid composition of the milk, the production technologies, and the starter cultures used in the product composition [3]. In Bulgaria and other Balkan countries, mixing is applied to different types of milk, as the amount of sheep's and goat's milk has decreased in recent years by approximately $35 \%$. The production of local artisanal traditional food products has increased significantly in recent years. Their production stimulates the local economy and improves the food culture. The output of traditional dairy foods is an example of solutions that aim at a more sustainable green economy, creating a prerequisite for developing specialized types of tourism in the regions.

Sheep's milk is a raw material widely used to produce traditional Bulgarian hard and soft cheeses [4]. In the different stages of lactation, the variety of food sources in grazing, climatic conditions, genetic and physiological characteristics of animals affect the physicochemical characteristics of the raw material [5].
Today, many researchers consider the influence of breeds and production methods (manual and automated) as a factor in the nutritional composition of milk from small ruminants $[4,5]$. Changes in the quantitative and qualitative composition of sheep's milk are thus variables that increase in early spring, maintain a trend of stability until mid-summer, and then follow a period of decline at the end of lactation [6].

The values of the constituent components of raw sheep's milk depend on the physiological features related to the natural course of milk reduction and the change in the photoperiod [4-6]. Variations in the composition of milk are also a result of the reproduction period, as there are hormonal changes in the animals associated with preparation for the subsequent pregnancy [7]. For these reasons, changes in the dry matter of sheep's milk are reported - $18-21 \%$, lipids $6-12 \%$, total protein $4-8 \%$, lactose 4 - $6 \%$ during different periods of lactation [8].

In Bulgaria, traditional artisanal dairy products prepared at home comply with Ordinance №26, which indicates the possibility of applying artisanal production of animal foods on the free market. The production of products such as hard cheeses (white brined cheese, yellow cheese), butter, cottage cheese, Tulum cheese, branza, and other local products, highlights the local traditions in products through the use of sheep's milk.

Sheep breeding and family sheep farms are part of the cultural heritage of Bulgaria. The seasonal nature of milk production in small ruminants necessitates the search for alternative forms to extend the shelf life of dairy products.

* Corresponding author: $\underline{\text { docstankov@gmail.com }}$ 
Through salting and storage in wooden baskets, pots, and earthenware in wells and basements, dairy products have accompanied the nutrition of Bulgarians all year round.

The aim of the present study was to evaluate the physicochemical and microbiological parameters of raw sheep's milk immediately after milking with the potential for the production of traditional artisanal cheese as part of the population's eating traditions in Bulgaria.

\section{Materials and Methods}

\subsection{Materials}

Raw sheep's milk was obtained by manual milking of Karakachan sheep breed in the village of Topolchane $\left(42.65^{\circ} \mathrm{N} 26.433333^{\circ} \mathrm{E}\right)$, Bulgaria.

Milk samples were obtained by the milking of thirty animals each morning. The values reported for the individual indicators were performed in three consecutive measurements. In the final results, they are presented with an average value through the program Microsoft Excel.

The samples were analyzed within 30-40 min after milk production. During the trials, the animals were fed entirely on pasture in the village grounds and were not treated with deworming drugs.

\subsection{Methods}

Determination of dry matter, dry non-fat residue, density, fat content, lactose, protein, mineral salts was made using a Lactoscan SFP Options Milk Analyzer.

The titratable acidity (TA) of the individual samples was determined by Thorner's method [9].

Potentiometric measurement of milk samples' active acidity was performed with a $\mathrm{pH}$ meter under standard test conditions

Total Bacterial Count was determined according to the procedure [10].

Determination of penicillin and tetracycline residues was made using a rapid quantification test (Twin Sensor).

The statistical analysis was performed with Microsoft Excel 2010, and the results were presented as mean value $\pm \mathrm{SD}(\mathrm{n}=3)$.

In order to determine the strength of the linear relationship between the variables considered, the following reference values were used [11].

\section{Results and Discussion}

The data (Fig. 1) shows a relatively stable trend in the dry matter, which was about $20 \%$ in sheep's milk. The levels of dry matter and the density of fresh sheep's milk indicated the production of artisanal dairy products, as they both (dry matter and density) participated in the formation of the textural indicators of the finished dairy products $[1,5]$.

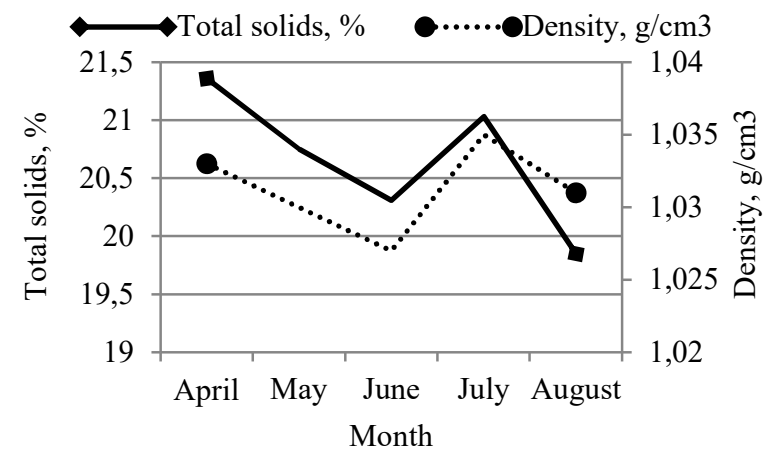

Fig. 1. Alteration in dry matter and density during lactation

The density of the milk, the amount of milk fat, and the dry non-fat residue were used to determine the dry matter. The dry fat-free residue during lactation in Karakachan sheep varied in relative values. The highest fat-free residue values for the period were reported in April (beginning of the milking campaign) - $12.76 \%$. It was higher $(10-11.45 \%)$ than previously reported [1214] obtained by sheep considered as cross between a Karakachan sheep and a Pleven black-headed ram. At the end of the lactation period, the values of the dry non-fat residue had decreased to $11.85 \%$, which is close to the previously reported mean values for milk from the Karakachan sheep breed [5].

The dry matter values in raw milk in April (21.36\%) decreased by about $10 \%$ in May and June (20.75 $20.31 \%$ ). In July, dry matter values were reported that were close to those measured in the spring $(21.03 \%)$. At the end of the lactation period (August), the dry matter was in closer range with that of the other months $(19.85 \%)$, and its decrease was due to climatic, physiological, and nutritional changes. These values were comparable to those previously reported by $[5,7,8]$.

A similar trend in dry matter in the milk of dairy breeds was found by other researchers $[15,16]$ where the values were in the range of 10.76 to $13.34 \%$ at the end of the lactation period.

The dry matter values were highest during the beginning of lactation at 14.08 and $14.18 \%$, and lowest in the middle of lactation.

The density of raw sheep's milk was at its lowest values in June $\left(1.027 \mathrm{~g} / \mathrm{cm}^{3}\right)$, and at its highest values it in July $\left(1.035 \mathrm{~g} / \mathrm{cm}^{3}\right)$ and April $\left(1.033 \mathrm{~g} / \mathrm{cm}^{3}\right)$. The changes in milk density resulted from changes in the composition of animal feed, which was associated with transitional climate change [8].

The values of the individual physicochemical parameters of sheep's milk depended on many factors such as breed, age, quantity and type of food, lactation period, season, method of milk production, etc. [12, 13].

The relationship between dry matter and sheep milk density was examined. The regression equation and the coefficient of determination are presented in Fig. 2. 


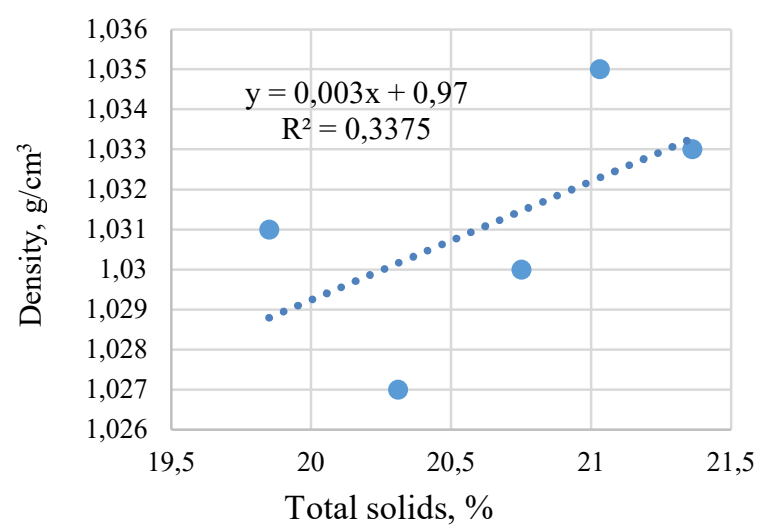

Fig. 2. Linear correlation between dry matter and density.

Correlation coefficient $\mathrm{R}=0.5809$ showed $\mathrm{a}$ significant linear relationship. Since $\mathrm{R}>0$, the dependence was positive, i.e., as the dry matter increased, so did the density; as the dry matter decreased, so did the density. The coefficient of determination was $\mathrm{R}^{2}=$ 0.3375 , i.e., approximately $34 \%$ of the changes in the dependent variable were due to changes in the independent variable.

A diet high in dietary fiber increased the amount of fat in milk [17], while the consumption of compound feed reduced this amount [18].

The higher values of winter fat reported by some researchers [7, 9, 11] could be explained by the application of dry compound feed. This feed increased fat levels by about $2 \%$ compared to the levels in April and May when the main diet was comprised of a variety of wild plant food. This could be due to lipolytic and proteolytic changes in leukocyte enzymes in the ewes. Data on changes in fat milk levels compared to the amount of dry matter in milk are presented in Fig. 3.

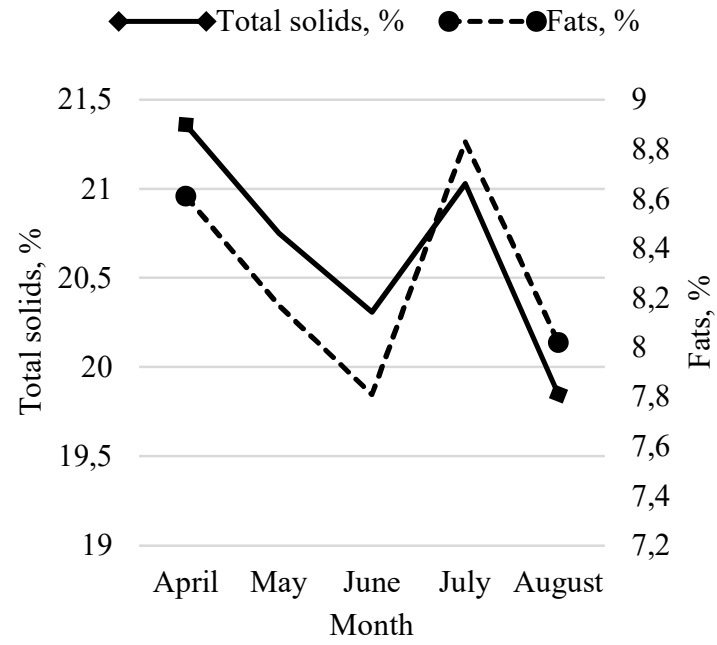

Fig. 3. Change in the amount of milk fat and dry matter during lactation

Study data indicated that the levels of milk fat were highest in July $(8.83 \%)$, and lowest in June (7.81\%) and at the end of lactation in August (8.02\%).

A similar trend was observed in dry matter levels, which might be due to the percentage ratio of individual nutrients in the milk. The botanical composition of pastures influenced the phenological stage of particular plant species, leading to milkweed's quantitative and qualitative fatty acid composition $[4,8]$.

The levels of dry matter and fat content in the middle of lactation period decreased, while increased again at the end of the lactation period. It was probably due to the change in the composition of the grassland and metabolic adaptability of the sheep to the change in climatic, physiological and nutritional characteristics of the period.

When comparing the dry matter with the fat content, $\mathrm{R}=0.7973$, which demonstrated a strong linear relationship, was again positive, i.e., as the dry matter increased, so did the fat content; as dry matter decreased, so did the levels of milk fat. The correlation coefficient was $\mathrm{R}^{2}=0.6357$, i.e., approximately $64 \%$ of the changes in the dependent variable were due to changes in the independent variable (Fig. 4).

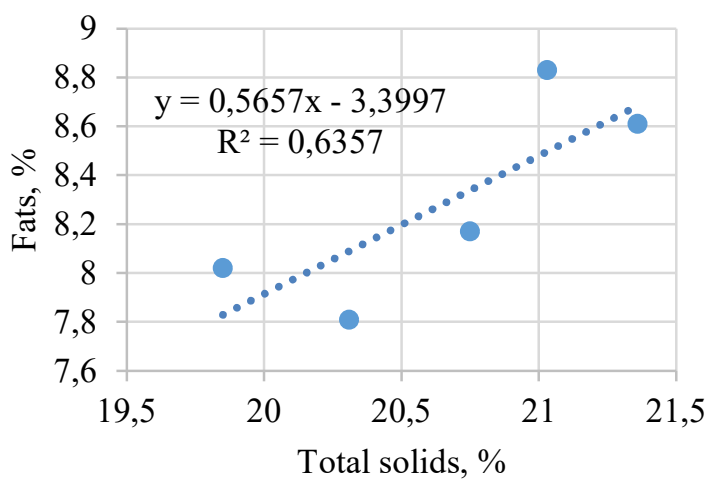

Fig. 4. Linear correlation between dry matter and milk fat.

The values of milk fat in the present study were close to those previously reported by other authors (5.91 $7.82 \%)[4,5,8,12,14]$. Correlation models for lactose content and density in raw sheep's milk have been developed. Lactose levels in raw sheep's milk during the study period (April-August) changed with increasing progression. For example, at the beginning of the milking campaign, the lactose level was $4.66 \%$ (April), but reached $5.13 \%$ in August. However, the increase in lactose levels in raw milk did not affect the density of milk [3, 4, 14] (Fig. 5).

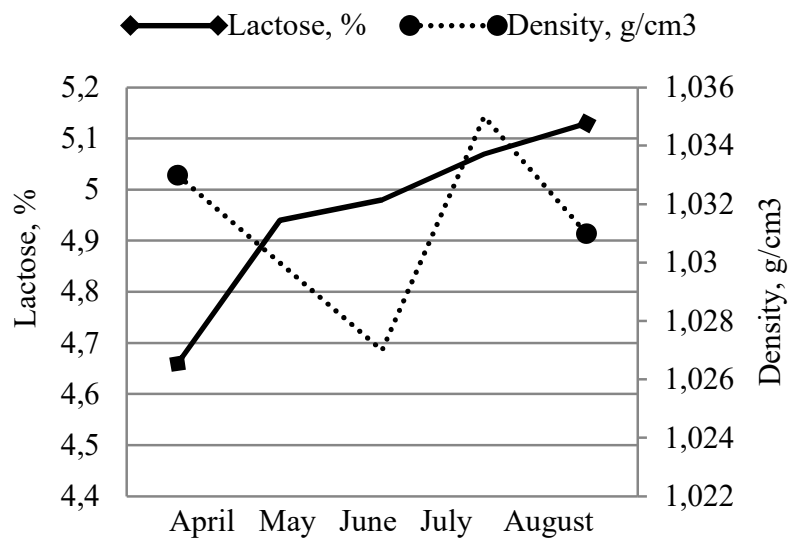

Fig. 5. Change in lactose quantity and density during lactation 
As a result of changes in the food consumed by the animals and the transition to their breeding season, changes in lactose levels affecting the $\mathrm{pH}$ of milk have also been reported (Fig. 6).

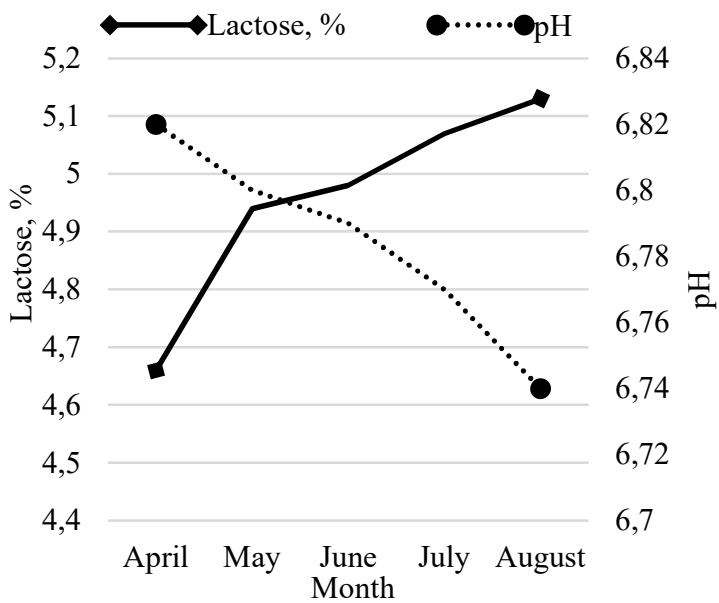

Fig. 6. Change in carbohydrate levels and $\mathrm{pH}$ during lactation

The progression of the lactose curve was similar to that of $\mathrm{pH}$. The increase in milk acidity indicated the accumulation of lactic acid due to lactose fermentation by lactic acid bacteria, which caused the destabilization of milk proteins during heating [19]. In addition to lactose, the acidity of sheep's milk was slightly affected by the presence of acids, salts, and proteins, mainly casein.

Differences in milk sugar levels in raw sheep's milk could be reduced during clinical and subclinical mastitis [20], which was observed in the initial periods of weaning from lambs and increased feeding rations in ewes. Milk sugar levels affected the acidity of milk, which changed its quality in the production of artisanal dairy products.

An inverse relationship to lactose levels in other small ruminants was reported in the study $[21,22]$, which could be explained by the change in the composition of the grassland, the physiological characteristics of the animals, and the beginning of the random campaign. All these environmental and physiological changes caused coordinated changes in the central nervous system, hormonal changes, and metabolic changes aimed at grouping nutrients and their accumulation in the form of reserves, such as preparation for the breeding season and another pregnancy.

Moreover, the mammary gland ceased to be an organ with a metabolic direction, which led to changes in the volume of milk secretion and the chemical composition of milk.

The total protein content in the milk of different groups of animals varied, and in the present study, our data were close to those previously reported by [4, 5, 22]. The change in the protein amount varied (Fig. 7). The total protein content in sheep milk from the Karakakchan sheep breed showed a downward phase in the early period of the milking campaign, reached equilibrium in the middle of the second month, followed by an upward phase in protein levels to $6.30 \%$ in June.

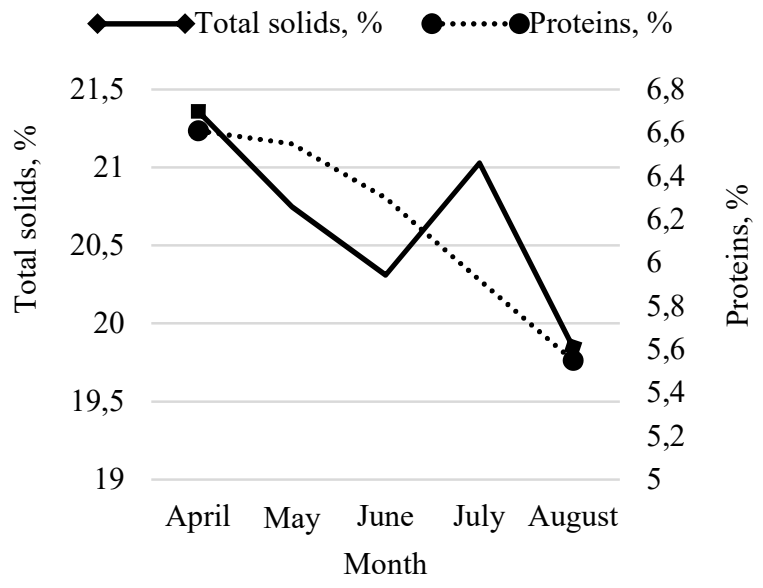

Fig. 7. Change in the amount of total protein and dry matter during lactation

As reported by other authors, the average total protein content in sheep $(5.19-6.22 \%)$ was higher than that of goats $(2.57-3.41 \%)$ in different lactation periods [23, 24, 25], which could be explained by species and genetic features in animals.

In the present study, the total protein content of sheep's milk exhibited some fluctuations in its quantitative composition. For example, the protein level at the beginning of the milking campaign was $6.61 \%$, but in the following stages, it tended to decrease. By the end of lactation, it had reached the lowest reported value $(5.55 \%)$ which was comparable to previously reported values for milk from the Karakachan sheep breed [7, 18, 21].

The data for a complex assessment of the correlation coefficients for the pair relationships among carbohydrates, density, and $\mathrm{pH}$ are presented in Table 1 .

Table 1. Correlation coefficients among carbohydrates, density and $\mathrm{pH}$

\begin{tabular}{|l|l|l|l|}
\hline & Lactose, $\%$ & Density, $\%$ & $\mathrm{pH}$ \\
\hline Lactose, \% & 1 & & \\
\hline Density, \% & $-0,0981$ & 1 & \\
\hline $\mathrm{pH}$ & $-0,9044$ & $-0,0648$ & 1 \\
\hline
\end{tabular}

The correlation coefficients among carbohydrates and density and $\mathrm{pH}$ and density were close to zero, indicating a lack of linear relationship. There was a very strong linear relationship between $\mathrm{pH}$ and the amount of lactose, as $\mathrm{R}$ $=-0.9044$. At $\mathrm{R}<0$, the dependence was negative, i.e., when the carbohydrate content increased, the $\mathrm{pH}$ decreased, and vice versa. The coefficient of determination was $\mathrm{R}^{2}=0.8180$ showing that approximately $82 \%$ of the changes in the dependent variable were due to changes in the independent one.

Change in titratable acidity during lactation were observed (Fig. 8). 


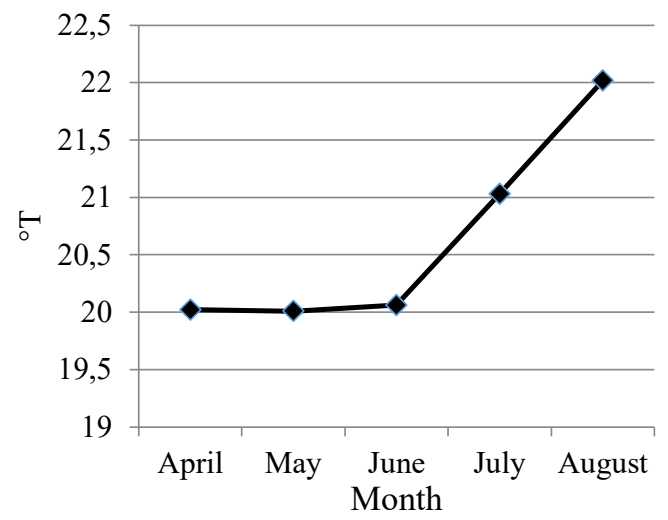

Fig. 8. Change in titratable acidity during lactation

At the beginning of the lactation period, the titratable acidity of raw sheep's milk was constant, and in the middle followed the growth rate. Due to the higher levels of proteins and minerals, the sheep's milk acidity was higher than other milk samples. The dependence that has been reported with increasing fat levels followed a tendency to increase the mineral content. In the present study, the mineral levels in raw sheep's milk followed the same trend (Fig. 9).

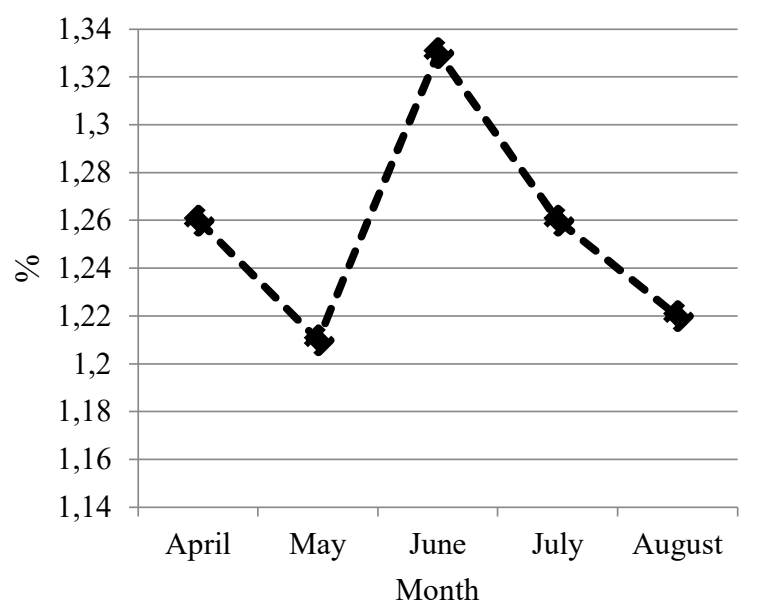

Fig. 9. Change in mineral composition during lactation

The mineral composition of the milk at the initial stage of lactation was $1.26 \%$, and at the end of the study period, the values reached $1.22 \%$. The data results indicated that the levels of mineral substances followed the changes in the amount of milk fat $[1,24,25]$.

The mineral composition of the milk affected its nutritional and biological evaluation and the technological processes in the formation of dairy products. For example, the content of soluble calcium salts had the most substantial influence on the coagulability of milk.

The methods of obtaining sheep's milk also determined the milk's microbial purity. The microbiological quality of the obtained sheep's milk was assessed up to 30-40 min after its production (Fig. 10).

The total number of mesophilic microorganisms obtained in the present study of raw milk from the Karakachan sheep breed was in the range $1.3 \times 10^{6}-$
$1.0^{4} \times 10^{6} \mathrm{CFU} / \mathrm{ml}$. The data were obtained from milk that was manually extracted for $20-25 \mathrm{~min}$.

The microbial safety of the obtained milk was lower than previously reported [26-28] obtained with manual milking of sheep. Proper technical manipulations during milking and the primary processing of milk were necessary in order to ensure low microbial contamination. On the other hand, the presence of penicillin and tetracycline residues in the composition of the tested milk was not detected.

\section{Conclusions}

The main physicochemical parameters of sheep's milk with potential for the production of traditional artisanal cheeses in Bulgaria were determined in the present study. The data showed that raw sheep's milk can be used as a raw material for the production of some traditional artisanal cheeses without prior pasteurization.

The initial temperature of the obtained milk (35 $36^{\circ} \mathrm{C}$ ) and the absence of inhibitors and the pasteurization process were favorable factors for lactic acid fermentation, with resultant formation of traditional artisanal products with typical textural and taste indicators. Further in-depth analyses will be carried out in order to validate the use of raw sheep's milk to produce traditional artisanal dairy products as an element of a nutritional diet.

\section{References}

1. S. Mamasov, S. Zukhra, T. Rakhmatullo, N. Sherzod, T. Giyos. IJPSAT. 26, 2 (2021)

2. N. Güzeler, D. Say, A. Kaçar. Gida. 35, 5 (2010).

3. C.D. Azzara, P.S. Dimmick. J. Dairy Sci. 68, 7, (1985)

4. V. Tsvetkova, L. Angelov. Bulg. J. Agric. Sci. 19, 1 (2011)

5. G. Mihaylova, G. Gerchev, P. Moeckel, G. Jahreis, G. Bulg. J. Vet. Med. 7, 3 (2004)

6. P. Damián, I. Sacchi, S. Reginensi, D. De Lima, J. Bermúdez. Arq. Bras. Med. Vet. Zootec. 60, 6 (2008)

7. G. Gerchev, G. Mihaylova. Biotechnol. Anim. Husb. 28, 2 (2012)

8. V. Tsvetkova, L. Angelov. Bulg. J. Agric. Sci. 16, 1 (2010)

9. BSS 1111-80. Milk and milk products. Determination of acidity (BIS, Sofia, 1980)

10. ISO 4833-2:2013. Microbiology of the food chainhorizontal method for the enumeration of microorganisms - Part 2: Colony count at $30^{\circ} \mathrm{C}$ by the surface plating technique (ISO, Geneva, 2013)

11. F.G. De Olivera Neto, R. Torkar, R. Feldt, R. L. Gren, C.A. Furia, Z. Huana. J. Sys. Soft. 1, 34 (2019)

12. N. Stancheva, N. Naidenova, G. Staikova. Maced. J. Anim. Sci. 1, 73-76 (2011)

13. J. P. Damián, I. Sacchi, S. Reginensi, D. De Lina, J. Bermúdez. Arq. Bras. Med. Vet. Zootec. 60, 6 (2008) 
14. E. Raicheva, T. Ivanova,E. Kipriotis, E. Kistanova. Biotechnol. Anim. Husb. 23, 5-6 (2007)

15. A.A.S. Rawya, K.A. Ahmed. Int. J. Lib. Arts Soc. Sci. 2, 67-72 (2014)

16. H.K. Mayer, G Fiechter. Int. Dairy J. 24, 57-63 (2012)

17. D. Zygoyiannis, Small Rum. Res. 62, 143-147 (2006)

18. G. Mihailova, T. Odjakova. J. Anim. Sci., 1, 1 (2011)

19. P. Morand-Fehr, V. Fedele, M. Decandia, Y. Le Frileux. Small Rum. Res. 68, 20-34 (2007)

20. M.R. Sanz Sampelayo, Y. Chilliard, P. Schmidely, J. Boza. Small Rum. Res. 68, 42-63 (2007)

21. G. Mihailova, T. Odjakova. Ecol. and Future 2, 2124 (2006)

22. N. Stancheva, N. Naidenova, G. Staikova. Food Proc. Ind. Mag. 9, 25 (2009)

23. M. Vilanova, M. Goncalves, M.T.M. Osorio, R. Esteves, V. Schmidt. Acta Sci. Vet. 36, 3 (2008)

24. I. M. Trancoso, M. A. Trancoso, A. P. Martins, L. B. Roseiro. Int. J. Dairy Technol. 63, 4 (2010)

25. Park, Y.W., Juárez, M., Ramos, M. Haenlein, G.F.W. Small Rum. Res. 68, 88-113 (2007)

26. A. Ariznabarreta, C. Gonzalo., F. San Primitivo. J. Dairy Sci. 6, 85 (2002)

27. G. Leitner, M, Chaffer, A. Shamay, F. Shapiro, U. Merin, E. Ezra, A. Saran, N. Silanikove. J Dairy Sci. 87, 46-52 (2004)

28. H.K. Mayer, G. Fiechter, Int. Dairy J. 24, 57-63 (2012) 